Evidence summaries

\title{
Ten years incidence of cancer in Iran; a systematic review and meta-analysis
}

\author{
Samira Beiranvand ${ }^{\mathrm{a}}$, Kourosh Zarea ${ }^{\mathrm{b}, *}$, Saeed Ghanbari ${ }^{\mathrm{c}}$, Hanna Tuvesson ${ }^{\mathrm{d}, \mathrm{e}}$, \\ Bijan Keikhaei $^{\mathrm{f}}$ \\ a Student Research Committee, Ahvaz Jundishapur University of Medical Sciences, Ahvaz, Iran \\ ${ }^{\mathrm{b}}$ Nursing Care Research Center in Chronic Diseases, School of Nursing and Midwifery, Ahvaz Jundishapur University of Medical Sciences, Ahvaz, Iran \\ c Department of Biostatistics, School of Medicine, Shiraz University of Medical Sciences, Shiraz, Iran \\ d Blekinge Institute of Technology, Department of Health, Karlskrona, Sweden \\ e Department of Health and caring sciences, Linnaeus University, Vaxjo, Sweden \\ ${ }^{\mathbf{f}}$ Health Research Institute, Research Center of Thalassemia and Hemoglobinopathy, Ahvaz Jundishapur University of Medical Sciences, Ahvaz, Iran
}

\section{A R T I C L E IN F O}

\section{Article history:}

Received 4 September 2017

Received in revised form 8 October 2017

Accepted 14 October 2017

Available online 16 October 2017

\section{Keywords:}

Cancer

Incidence of cancer

epidemiology of cancer

cancer occurrence

cancer in Iran

\begin{abstract}
A B S T R A C T
Background: Designing and implementation of screening programs depend on greatly epidemiologic basic data in every country. Also Variation in the incidence of various cancers in our country has been a favorite topic.

Objectives: This systematic review was conducted to provide an overall perspective about incidence, geographical and age distribution of cancers in Iran.

Methods: A comprehensive search were done according to MOOSE guideline criteria in national and international databases for selecting eligible articles from 2005 to 2015. After screening titles and abstracts, duplicated and irrelevant studies were excluded. Selected papers are written in Persian or English. The standard error of the cancer incidence was calculated based on the binomial distribution. Because of the significant heterogeneity observed among the results, we used a random-effects model combine the results of the primary studies. Moreover, a sensitivity analysis was undertaken to explore the effects of the risk of bias and other sources of heterogeneity.

Results: Overall 16 articles met eligibility criteria for inclusion. The total incidence of cancer was 19.4 and 17.2 per hundred thousand of people in males and females respectively. The five most common cancers in male were: Lymphoma, leukemia, esophagus, stomach, colorectal and in the female are: breast, colorectal, stomach, thyroid and esophagus. The highest incidence rate was seen in Golestan Province and in the age group over 65 years.

Conclusion: According to increasing incidence rate of cancers in Iran, Development, holding and accomplish of universal public cancer control program should be the first precedence for health policy. (c) 2017 Published by Elsevier, a division of RELX India, Pvt. Ltd on behalf of INDIACLEN.
\end{abstract}

\section{Introduction}

Cancer is a principal cause of death worldwide ${ }^{1}$ and it is expected to locate the cause of death in the prior rank of ischemic heart disease. ${ }^{2}$ Cancer is also a public health problem in Iran with cancer being the third cause of death. ${ }^{3}$ Moreover, the number of

\footnotetext{
* Corresponding author at: Nursing Care Research Center in Chronic Diseases, Nursing Department, 2floor, School of Nursing and Midwifery, Ahvaz Jundishapur University of Medical Sciences, Ahvaz, Iran. Tel.: +9833738622.

E-mail addresses: Beiranvandsamira@yahoo.com (S. Beiranvand), Zarea_k@ajums.ac.ir, kourosh1685@gmail.com (K. Zarea), ghanbarisa@sums.ac.ir (S. Ghanbari), hanna.tuvesson@bth.se (H. Tuvesson), keikhaeib@yahoo.com (B. Keikhaei).
}

cancer cases in low- and middle-income countries is expected to grow ${ }^{1}$ and the mortality rate owing to cancer in Iran is also on the rise. ${ }^{3}$ Iran as a developing nation has been described to be in an epidemiologic evolution, moving from contagious to non- contagious diseases. Despite, cancer is the third leading cause of death in Iran, it's related deaths are increasing during last decades. ${ }^{3}$ According to statistics from WHO, the total number of cancer deaths was 395000 in the year $2014 .{ }^{4}$ Population aging, increased life expectancy and rising faced with peripheral carcinogens as well as high-risk behaviors, particular smoking, have led to an increase in cancer incidence. ${ }^{5,}$. Designing and execution of screening programs depend on greatly epidemiologic basic data in every country worldwide, contains; evaluation concerning the elaboration of the problem, identification of moderate and high- 
risk populations, determination the most prevalent tumor location and also identifying the most frequent age of diagnosis. ${ }^{7}$ Incidence refers to the number of new cases of disease that occur in a given population at a specified time period. ${ }^{8}$ In scheduled services, indexes like incidence can be useful for expansion of procedures for service delivery. Differences concerning the various cancer incidence in Iran has become a considerable issue and requires to be recorded accurately cancer cases which provide exact information about the incidence, burden of disease and variations in mortality and morbidity each year. ${ }^{9}$ Therefore, current information concerning the incidence of cancer in Iran is little and incomplete. This systematic review and meta-analysis, aimed to estimate the incidence of cancer in Iran and to explain incidental differences that may help in the design and establishment of early cancer detection programs and investigate population risk factors.

\section{Materials and Methods}

In this study, systematic review methods were used to identifying relevant research concerning the incidence of cancer and providing an overall perspective about incidence, geographical and age distribution of cancers in Iran.

\subsection{Search Strategy}

In this systematic review, a comprehensive computer-assisted publication search was conducted using the Google Scholar, PubMed, Science Direct, and Scopus databases, and via Persian literatures in Iranian databases including Indexing Articles Published in Iran Biomedical Journals (Iran Medex), Country Magazines Database (Mag Iran), and Scientific Information Database (SID). In addition, manual reviews of the reference lists of studies identified during electronic searches were done. Also other related electronic links were checked. The literature search was also provided by a handy review of 'grey literature'; conference presentations, project reports, government and health-care organizational reports. The initial search was performed with the medical subject headings (MeSH) keywords. Searches included the following keywords: cancer; incidence of cancer; epidemiology of cancer; cancer occurrence and cancer in Iran. The search results were restricted to these keywords in article titles. The keywords were used separately and in combination forms.

\subsection{Study Selection}

All cross-sectional descriptive studies investigating the incidence, geographical and age distribution of cancers in Iran were eligible for initial inclusion. We extracted full texts or abstracts of the papers, documents, reports and other evidence found by advanced search.

Two review author screened titles and abstracts of the papers identified from the search to eliminate duplicate and irrelevant publications. The inclusion criteria were; 1 ) studies that reported results concerning cancer incidence in Iran, 2) studies published between 2005 and 2015 and 3) studies published in English and Persian language. Based on the title and abstract screening, the exclusion criteria for selecting eligible articles were: 1) nonresearch articles (all type of letters, comments, and editorial), 2) animal studies, and 3) the studies which did not report the total number of patients and population at risk.

The risk of publication bias was reduced by interviewing some experts and staff of the research centers to provide probable unpublished papers. Finally, another researcher randomly evaluated this search and found that all relevant studies had been collected in the search. In addition, we used Egger's test and funnel plots to evaluate the degree of publication bias. In order to prevent the republication bias, we investigated the results to identify and exclude the repeated studies.

\subsection{Quality Assessment}

This systematic review was performed according to the MOOSE (Meta-Analyses of Observational Studies in Epidemiology) checklists. ${ }^{10}$ This checklist was used in previous studies. ${ }^{11}$ This checklist was designed to avoid any individual bias influences on the quality score. In addition, MOOSE checklists contents including 6 sections assessing different aspects of methodology such as how to report

Table 1

Studies included in the systematic review and meta-analysis of the incidence of cancer in Iran.

\begin{tabular}{|c|c|c|c|c|c|c|c|}
\hline No & First Author & Province & Year & No. of Cases & Male (\%) & $\begin{array}{c}\text { Female } \\
(\%)\end{array}$ & Mean age (Years) \\
\hline 1 & Semnani et al & Golestan & 2006 & 5143 & 59.6 & 40.4 & 60 \\
\hline 2 & Mehrabani et al & Fars & 2008 & 3115 & 47.9 & 52.1 & NA \\
\hline 3 & Somi et al & East Azarbaijan & 2006 & 5417 & 61.7 & 37.6 & 59.45 \\
\hline 4 & Somi et al & East Azarbaijan & 2008 & 4922 & 56.8 & 43 & 60.2 \\
\hline 5 & Mirzaei et al & All Provinces & 2015 & 25952 & 54 & 46 & NA \\
\hline 6 & Mousavi et al & All Provinces & 2009 & 55855 & 43.8 & 56.2 & NA \\
\hline 7 & Safaee et al & All Provinces & 2012 & 19617 & 44 & 56 & 58.9 \\
\hline 8 & Zeinalzadeh et al & Ardebil & 2015 & 3832 & 53.5 & 46.5 & 58.1 \\
\hline 9 & Taefi et al & $\begin{array}{c}\text { Gilan } \\
\text { Golestan } \\
\text { Ardebil } \\
\text { Mazandaran } \\
\text { Kerman }\end{array}$ & 2008 & 626 & 43.2 & 56.8 & 63 \\
\hline 10 & Esmaeelnasab et al & Kordestan & 2006 & 1299 & 61.7 & 38.3 & NA \\
\hline 11 & Hashiani et al & Fars & 2012 & 743 & 72 & 28 & 63 \\
\hline 12 & Mirzaei et al & Tehran & 2014 & 7429 & 64.7 & 35.3 & NA \\
\hline 13 & Kohi et al & All Provinces & 2015 & 27898 & 82.2 & 17.8 & NA \\
\hline 14 & Ansari et al & $\begin{array}{l}\text { Ardebil } \\
\text { Gilan } \\
\text { Mazandaran } \\
\text { Golestan } \\
\text { Kerman }\end{array}$ & 2006 & 2055 & 54.9 & 44 & NA \\
\hline 15 & Zahedi et al & Kerman & 2005 & 1303 & 59.1 & 40.8 & 51.5 \\
\hline 16 & Khabazkhub et al & Tehran & 2009 & 34269 & 54 & 46 & NA \\
\hline
\end{tabular}


background, search strategy, methods, results and conclusions. Each section includes more detailed questions.

\subsection{Data Extraction}

The following information was extracted by two researchers from the all of involving studies: the first author name (e.g. Semnani et al); place of the study (the relevant province), year of publication; study population; the baseline proportion of male and female and mean age of patients (c.f. Table 1). Data was also derived related to a number of cancer cases and types of cancers in relation to a province, sex and age. The above-extracted data were entered into a Microsoft Excel spreadsheet in order to minimize potential errors. Conflicting results in each stage were discussed by authors. Finally, extracted data was a revision by a senior researcher.

\subsection{Statistical Analysis}

Stata Version 11. The software was used for analyzing the data. For calculating the cancer incidence, was divided by the total number of person-years of observation, for every of the entered

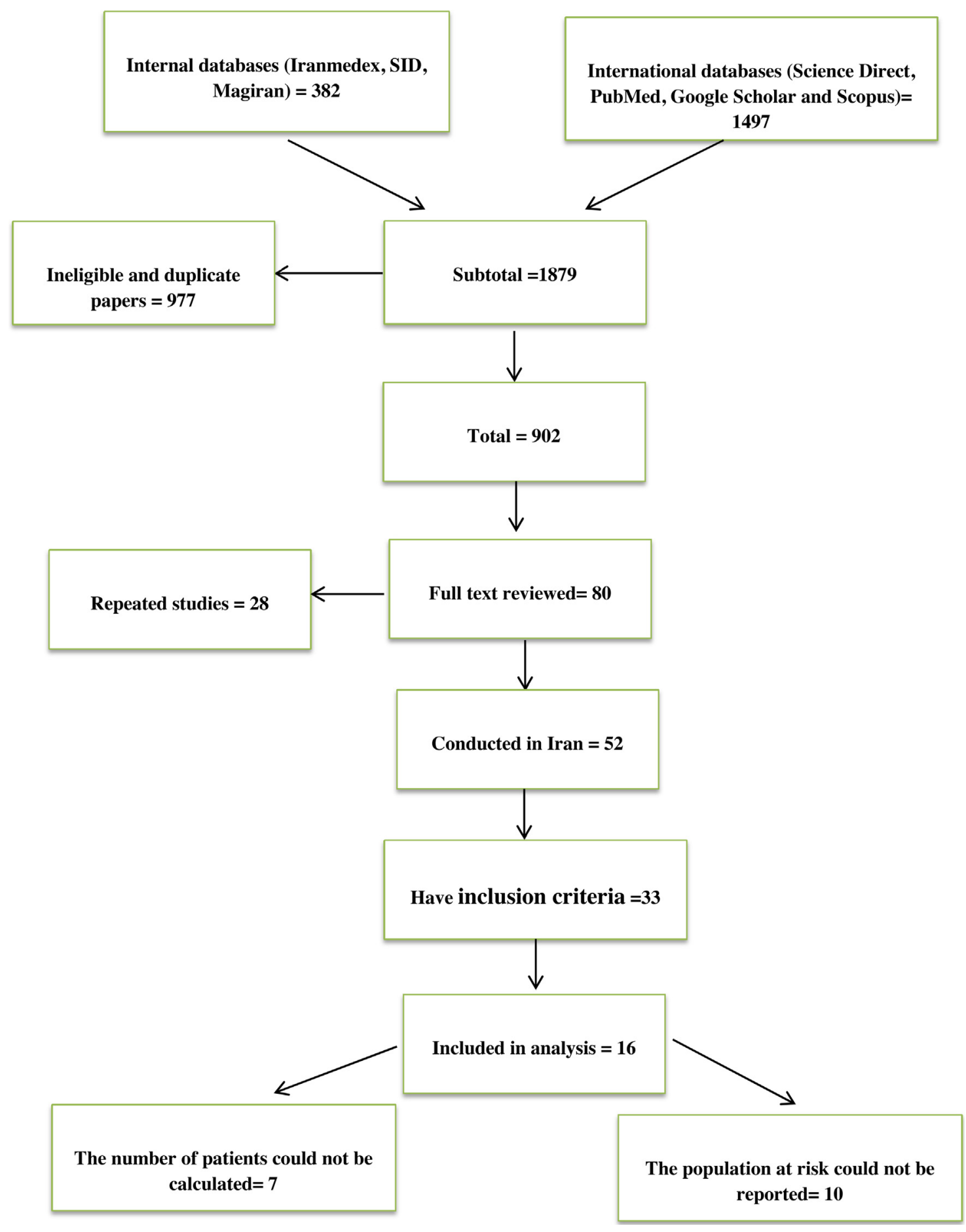

Fig. 1. Search strategy used and number of studies included at each stage of the meta-analysis. 
Table 2

Geographical distribution of cancer incidence in Iran in the systematic review.

\begin{tabular}{|c|c|c|c|c|c|c|}
\hline No. & Type of Cancer & Province & Pooled estimation & 95\% confidence interval & $\%$ Weight & I-Squared (\%) \\
\hline \multirow[t]{3}{*}{1} & Adrenal \& other endocrine gland & East Azerbaijan & 0.485 & $0.324-0.646$ & 1.18 & 0 \\
\hline & & Fars & 0.426 & $0.289-0.562$ & 1.63 & 78.6 \\
\hline & & All Provinces & 0.112 & $0.095-0.130$ & 97.19 & 99.9 \\
\hline \multirow[t]{5}{*}{2} & Billiary ducts & Ardebil & 0.011 & -0.004 to 0.025 & 47.53 & 0 \\
\hline & & Gilan & 0.134 & $0.082-0.187$ & 3.74 & 0 \\
\hline & & Golestan & 0.014 & -0.003 to 0.031 & 35.65 & 0 \\
\hline & & Kerman & 0.128 & $0.082-0.175$ & 4.76 & 82 \\
\hline & & Mazandaran & 0.061 & $0.025-0.096$ & 8.32 & 61.1 \\
\hline \multirow[t]{6}{*}{3} & Bladder & Ardebil & 4.674 & $4.117-5.230$ & 0.54 & 16.1 \\
\hline & & East Azerbaijan & 1.316 & $1.051-1.581$ & 2.38 & 99.5 \\
\hline & & Fars & 0.554 & $0.398-0.709$ & 6.89 & 98.2 \\
\hline & & Golestan & 3.631 & $2.931-4.330$ & 0.34 & 99.1 \\
\hline & & Kordestan & 1.143 & $0.766-1.520$ & 1.18 & 95.2 \\
\hline & & All Provinces & 1.368 & $1.325-1.412$ & 88.66 & 99.9 \\
\hline \multirow[t]{3}{*}{4} & Bone & East Azerbaijan & 0.825 & $0.615-1.034$ & 48.67 & 72 \\
\hline & & Fars & 1.147 & $0.922-1.371$ & 42.58 & 0 \\
\hline & & Golestan & 1.814 & $1.320-2.308$ & 8.76 & 91.8 \\
\hline \multirow[t]{5}{*}{5} & Brain \& CNS & Kordestan & 0.129 & $0.003-0.256$ & 9.14 & 0 \\
\hline & & East Azerbaijan & 2.470 & $2.107-2.832$ & 1.12 & 0 \\
\hline & & Fars & 1.870 & $1.584-2.157$ & 1.79 & 83.4 \\
\hline & & Golestan & 2.257 & $1.706-2.809$ & 0.48 & 94.3 \\
\hline & & All Provinces & 0.602 & $0.561-0.643$ & 87.47 & 95.7 \\
\hline \multirow[t]{6}{*}{6} & Breast & Ardebil & 2.329 & $1.936-2.722$ & 5.65 & 99.8 \\
\hline & & East Azerbaijan & 10.906 & $9.828-11.984$ & 0.75 & 0 \\
\hline & & Fars & 0.582 & $0.422-0.741$ & 34.25 & 99.8 \\
\hline & & Golestan & 26.432 & $23.764-29.100$ & 0.12 & 0 \\
\hline & & Kordestan & 2.134 & $1.406-2.862$ & 1.65 & 99.8 \\
\hline & & All Provinces & 5.434 & $5.310-5.557$ & 57.58 & 0 \\
\hline \multirow[t]{6}{*}{7} & Bronchus \& Lung & Ardebil & 3.515 & $3.032-3.998$ & 1.11 & 0 \\
\hline & & East Azerbaijan & 2.450 & $2.089-2.811$ & 1.99 & 98 \\
\hline & & Fars & 1.399 & $1.224-1.575$ & 8.46 & 95.8 \\
\hline & & Golestan & 1.335 & $0.911-1.758$ & 1.44 & 95 \\
\hline & & Kordestan & 0.902 & $0.567-1.237$ & 2.32 & 91.7 \\
\hline & & All Provinces & 1.099 & $1.043-1.154$ & 84.68 & 99.9 \\
\hline 9 & Colorectal & Ardebil & 4.223 & $3.693-4.752$ & 0.40 & 0 \\
\hline & & East Azerbaijan & 6.853 & $6.422-7.283$ & 0.60 & 99.1 \\
\hline & & Fars & 2.205 & $1.894-2.516$ & 1.16 & 73 \\
\hline & & Golestan & 11.883 & $10.618-13.148$ & 0.07 & 97.3 \\
\hline & & Kerman & 9.546 & $8.590-10.503$ & 0.12 & 100 \\
\hline & & Kordestan & 0.993 & $0.642-1.344$ & 0.91 & 0 \\
\hline & & Tehran & 1.776 & $1.691-1.861$ & 15.51 & 0 \\
\hline & & All Provinces & 1.001 & $0.694-1.038$ & 81.23 & 97.5 \\
\hline 10 & Esophagus & Ardebil & 4.464 & $3.920-5.008$ & 2.09 & 0 \\
\hline & & East Azerbaijan & 8.734 & $8.248-9.220$ & 2.62 & 99.6 \\
\hline & & Fars & 0.720 & $0.543-0.898$ & 19.62 & 46.3 \\
\hline & & Golestan & 51.240 & $48.614-53.866$ & 0.09 & 96.2 \\
\hline & & Kerman & 3.535 & $2.953-4.117$ & 1.83 & 93.5 \\
\hline & & Kordestan & 2.419 & $1.871-2.967$ & 2.06 & 54.4 \\
\hline & & All Provinces & 3.098 & $3.005-3.191$ & 71.68 & 99.9 \\
\hline 11 & Gallbladder & Ardebil & 0.133 & $0.081-0.186$ & 8.93 & 79.2 \\
\hline & & East Azerbaijan & 0.613 & $0.484-0.741$ & 1.46 & 84.2 \\
\hline & & Fars & 0.086 & $0.024-0.147$ & 6.46 & 0 \\
\hline & & Gilan & 0.100 & $0.055-0.145$ & 11.93 & 89.1 \\
\hline & & Golestan & 0.041 & $0.014-0.068$ & 33.41 & 91.2 \\
\hline & & Kerman & 0.312 & $0.240-0.384$ & 4.63 & 95.4 \\
\hline & & Mazandaran & 0.243 & $0.173-0.314$ & 4.90 & 4.1 \\
\hline & & All Provinces & 0.307 & $0.278-0.337$ & 28.27 & 97.7 \\
\hline 12 & Kidney & East Azerbaijan & 1.017 & $0.784-1.250$ & 3.80 & 87 \\
\hline & & Fars & 0.429 & $0.292-0.566$ & 10.97 & 0 \\
\hline & & Golestan & 1.530 & $1.076-1.984$ & 1 & 91.2 \\
\hline & & All Provinces & 0.877 & $0.828-0.927$ & 84.22 & 100 \\
\hline 13 & Larynx & East Azerbaijan & 0.199 & $0.096-0.302$ & 5.01 & 95.9 \\
\hline & & Fars & 0.127 & $0.053-0.202$ & 9.53 & 96.9 \\
\hline & & Golestan & 0.255 & $0.070-0.440$ & 1.55 & 93.2 \\
\hline & & All Provinces & 0.454 & $0.429-0.480$ & 83.91 & 100 \\
\hline 14 & Leukemia & Ardebil & 2.481 & $2.076-2.887$ & 3.33 & 54.9 \\
\hline & & East Azerbaijan & 3.366 & $2.943-3.790$ & 3.06 & 96.3 \\
\hline & & Fars & 6.150 & $5.631-6.669$ & 2.03 & 95.2 \\
\hline & & Golestan & 4.009 & $3.274-4.744$ & 1.02 & 82.2 \\
\hline & & Kordestan & 0.305 & $0.110-0.499$ & 14.48 & 78.1 \\
\hline & & All Provinces & 2.584 & $2.499-2.668$ & 76.08 & 100 \\
\hline 15 & Liver & East Azerbaijan & 1.542 & $1.338-1.746$ & 1.21 & 97.4 \\
\hline & & Fars & 0.359 & $0.234-0.485$ & 3.20 & 0 \\
\hline & & Golestan & 0.992 & $0.626-1.357$ & 0.38 & 92.7 \\
\hline & & Kerman & 1.765 & $1.353-2.176$ & 0.30 & 81 \\
\hline & & All Provinces & 0.190 & $0.167-0.213$ & 94.92 & 97.7 \\
\hline
\end{tabular}


Table 2 (Continued)

\begin{tabular}{|c|c|c|c|c|c|c|}
\hline No. & Type of Cancer & Province & Pooled estimation & 95\% confidence interval & \% Weight & I-Squared (\%) \\
\hline \multirow[t]{5}{*}{16} & Lymph nodes & East Azerbaijan & 2.636 & $2.106-3.166$ & 1.75 & 0 \\
\hline & & Fars & 2.605 & $2.267-2.942$ & 4.31 & 95.9 \\
\hline & & Golestan & 4.277 & $3.518-0.036$ & 0.85 & 0 \\
\hline & & Kordestan & 0.517 & $0.264-0.771$ & 7.65 & 0 \\
\hline & & All Provinces & 2.064 & $1.988-2.140$ & 85.43 & 100 \\
\hline \multirow[t]{4}{*}{17} & Oral cavity & East Azerbaijan & 1.476 & $1.195-1.756$ & 1.48 & 72.5 \\
\hline & & Fars & 0.304 & $0.189-0.420$ & 8.74 & 70 \\
\hline & & Golestan & 6.496 & $5.561-7.432$ & 0.13 & 95.4 \\
\hline & & All Provinces & 0.932 & $0.896-0.968$ & 89.64 & 99.9 \\
\hline \multirow[t]{8}{*}{18} & Pancreas & Ardebil & 0.116 & $0.068-0.165$ & 16.34 & 0 \\
\hline & & East Azerbaijan & 0.695 & $0.502-0.887$ & 1.05 & 48 \\
\hline & & Fars & 0.304 & $0.189-0.420$ & 2.90 & 0 \\
\hline & & Gilan & 0.462 & $0.365-0.559$ & 4.12 & 82.4 \\
\hline & & Golestan & 0.143 & $0.093-0.193$ & 15.34 & 85 \\
\hline & & Kerman & 0.378 & $0.298-0.458$ & 6.10 & 79.2 \\
\hline & & Mazandaran & 0.382 & $0.293-0.470$ & 4.99 & 48.6 \\
\hline & & All Provinces & 0.282 & $0.254-0.310$ & 49.16 & 99.8 \\
\hline \multirow[t]{4}{*}{19} & Pharynx & East Azerbaijan & 0.361 & $0.165-0.557$ & 3.30 & 99.3 \\
\hline & & Fars & 0.664 & $0.494-0.835$ & 4.37 & 63.9 \\
\hline & & Golestan & 1.122 & $0.733-1.510$ & 0.84 & 75 \\
\hline & & All Provinces & 0.996 & $0.958-1.033$ & 91.49 & 99.9 \\
\hline \multirow[t]{7}{*}{20} & Skin & Ardebil & 5.964 & $5.336-6.593$ & 0.24 & 93.1 \\
\hline & & East Azerbaijan & 8.373 & $7.705-9.041$ & 0.21 & 97.8 \\
\hline & & Fars & 0.423 & $0.287-0.559$ & 5.07 & 0 \\
\hline & & Golestan & 14.006 & $12.633-15.379$ & 0.05 & 98.5 \\
\hline & & Kordestan & 3.967 & $3.265-4.669$ & 0.19 & 93.5 \\
\hline & & Tehran & 1.460 & $1.398-1.523$ & 24.32 & 99.5 \\
\hline & & All Provinces & 0.482 & $0.445-0.518$ & 69.92 & 100 \\
\hline \multirow[t]{3}{*}{21} & Small intestine & East Azerbaijan & 1.067 & $0.825-1.309$ & 7.46 & 69.5 \\
\hline & & Fars & 0.114 & $0.043-0.185$ & 87.46 & 0 \\
\hline & & Kerman & 0.898 & $0.605-1.191$ & 5.08 & 0 \\
\hline \multirow[t]{7}{*}{22} & Stomach & Ardebil & 7.175 & $6.485-7.865$ & 1.38 & 80.9 \\
\hline & & East Azerbaijan & 10.829 & $10.288-11.370$ & 2.24 & 99.8 \\
\hline & & Fars & 1.851 & $1.566-2.136$ & 8.10 & 96.7 \\
\hline & & Golestan & 17.149 & $15.629-18.668$ & 0.28 & 99.5 \\
\hline & & Kerman & 10.863 & $9.842-11.883$ & 0.63 & 98.6 \\
\hline & & Kordestan & 3.609 & $2.939-4.279$ & 1.47 & 96.8 \\
\hline & & All Provinces & 2.742 & $2.655-2.830$ & 85.89 & 99 \\
\hline \multirow[t]{6}{*}{23} & Thyroid & Ardebil & 2.170 & $1.790-2.549$ & 0.23 & 0 \\
\hline & & East Azerbaijan & 1.356 & $1.087-1.642$ & 0.46 & 96.6 \\
\hline & & Fars & 0.537 & $0.384-0.691$ & 1.40 & 65.3 \\
\hline & & Golestan & 3.272 & $2.608-3.936$ & 0.07 & 62.5 \\
\hline & & Kordestan & 0.194 & $0.039-0.349$ & 1.37 & 100 \\
\hline & & All Provinces & 0.245 & $0.226-0.263$ & 96.48 & 50 \\
\hline \multirow[t]{7}{*}{24} & Total & Ardebil & 65.765 & $63.677-67.852$ & 0.06 & 94.6 \\
\hline & & East Azerbaijan & 69.144 & $67.777-70.511$ & 0.15 & 99.3 \\
\hline & & Fars & 10.672 & $10.113-11.230$ & 0.90 & 99.9 \\
\hline & & Golestan & 173.718 & $168.886-178.551$ & 0.01 & 99.5 \\
\hline & & Kerman & 31.411 & 29.677-33.146 & 0.09 & 97.7 \\
\hline & & Kordestan & 20.615 & $19.015-22.215$ & 0.11 & 97.6 \\
\hline & & All Provinces & 17.257 & $17.131-17.384$ & 17.62 & 100 \\
\hline
\end{tabular}

studies. Also the incidence rate of each province was calculated by dividing the number of new patients with cancer on the persons who participated in every study. The standard error of the cancer incidence was calculated based on the $\chi^{2}$ distribution. Heterogeneity between the results of the studies was detected using Isquared index and Cochrane test. Moreover, a sensitivity analysis was conducted to identify the studies influencing the heterogeneity. Random effects model was used to estimate the pooled incidence of cancer in Iran. Forest plots were designed to illustrate a point and pooled incidence of most common cancers in male and females and 95\% confidence interval of them.

\subsection{Results}

The initial search strategies yielded 1879 references for all mentioned databases. After restricting the search strategy and having excluded duplicated articles, a total of 902 studies were identified; cancer (355), epidemiology of cancer (85), incidence of cancer (454), cancer occurrence (85), and cancer in Iran (278). In the next step through reviewing titles and abstracts, 802 articles were omitted. Further screening regarding the inclusion/exclusion criteria and quality assessment checklist were only identified 33 potential studies. Of these, seven studies were excluded because the number of patients did not calculate. Another 10 studies did not report population at risk and therefore were excluded. Sixteen studies ${ }^{12-27}$ were deemed eligible and entered the meta-analysis process (Fig. 1). This review included recent research literature concerning the epidemiology and incidence of cancer. Only Iranian researchers were reviewed to survey the incidence of cancer. Publication dates of the studies varied between 2005 and 2015. Eight articles were written in English. Four studies have investigated the incidence of various types of cancers and 7 articles were examined the incidence of digestive system cancers (e.g. esophageal, colorectal, pancreas and biliary ducts cancers). One paper was about lung cancer incidence and 1 study has only investigated the incidence of skin cancer. Locations of the 16 studies were Golestan, East Azerbaijan, Ardebil, Kerman, Kurdistan, Fars, Gilan, Tehran and Mazandaran. Five of the included 
studies investigated the incidence of cancers throughout the country. Total cancer patients were 199475 for all studies. The age categories of the included studies were similar and comprised the following age groups; 0-14, 15-24, 25-34, 35-44, 45-54, 55-64 and $\geq 65$ years. All 16 studies reported the incidence of each type of cancer in connection to both sexes and all age categories. All included studies supply information which could be applied for analyzing of the incidence of cancer in Iran. However, there was evidence of considerable heterogeneity in this pooled analysis. The results of measured pooled incidence for each cancer are presented in Table 2.

This systematic review showed that overall incidence of cancer was 19.4 and 17.2 per 100000 in males and females respectively. (95 percent confidence interval (CI): 19.2, 19.6-17.05, 17.4 respectively). Based on our results, in males the five most prevalent cancers (ASR) are: Lymphoma (10.8 per 100,000), leukemia (5.9 per 100,000$)$, esophagus (4.7 per 100,000$)$, stomach (3.7 per 100,000$)$ and colorectal (2.9 per 100,000). Also the five most frequent cancers in females are: breast $(8.7$ per 100,000$)$, colorectal (4.3 per 100,000$)$, stomach ( 2.52 per 100,000$)$, thyroid (2.2 per 100,000$)$, and esophagus (2.03 per 100,000$)$.

Also results of this systematic review show that geographical distribution of types of cancers in Iran provinces (by ASR) are Golestan (173.7 per 100 000), East Azerbaijan (69.1 per 100 000), Ardebil (65.7 per 100 000), Kerman (31.4 per 100 000), Kurdistan (20.6 per 100 000), Fars (10.7 per 100.000), Gilan (19.3 per 100.000) and Mazandaran (17.2 per 100 000) respectively. Forest plots were designed to illustrate a point and pooled incidence of most common cancers in male and females and 95\% confidence interval of them based on random effects. In these plots, size of each box indicated the study weight, while the crossing lines showed the 95\% confidence intervals (Figs. 2 and 3 ). In addition, the results of Egger's test $(P=0.349)$ and funnel plots suggests the absence of significant publication bias affecting studies included in this review (Fig. 4).

\section{Discussion \& Conclusion}

This meta-analysis showed that the total cancer incidence in Iran was higher in men than women. This is similar to previous research of cancer in Iran, where the sex ratio of cancer in men was higher than women. ${ }^{15},{ }^{28}$ The present review indicates a somewhat higher incidence of cancer in men compared to women, still gender differences were not substantial. One reason for this could be appointed to similarities in contributing factors in males and females. However, in men is more prevalent hazardous behaviors such as smoking, alcohol consumption and drug abuse in Iran but then again Iranian women are subjected to other cancer risk factors such as immobility. On the other hand, in our country cause of the disease may be more genetic rather than environmental and can effect on both males and females evenly. ${ }^{18}$ Other international studies as well as have mentioned the same results. ${ }^{729}$

Based on our results the most common cancers in males and female are Lymphoma and breast respectively. As this regard results of some studies in this field are as follows; Mousavi et al based on the National Cancer Registry Report from 2003 to 2006 noticed which breast cancer and stomach cancer were the most prevalent cancers among Iranian women and men respectively

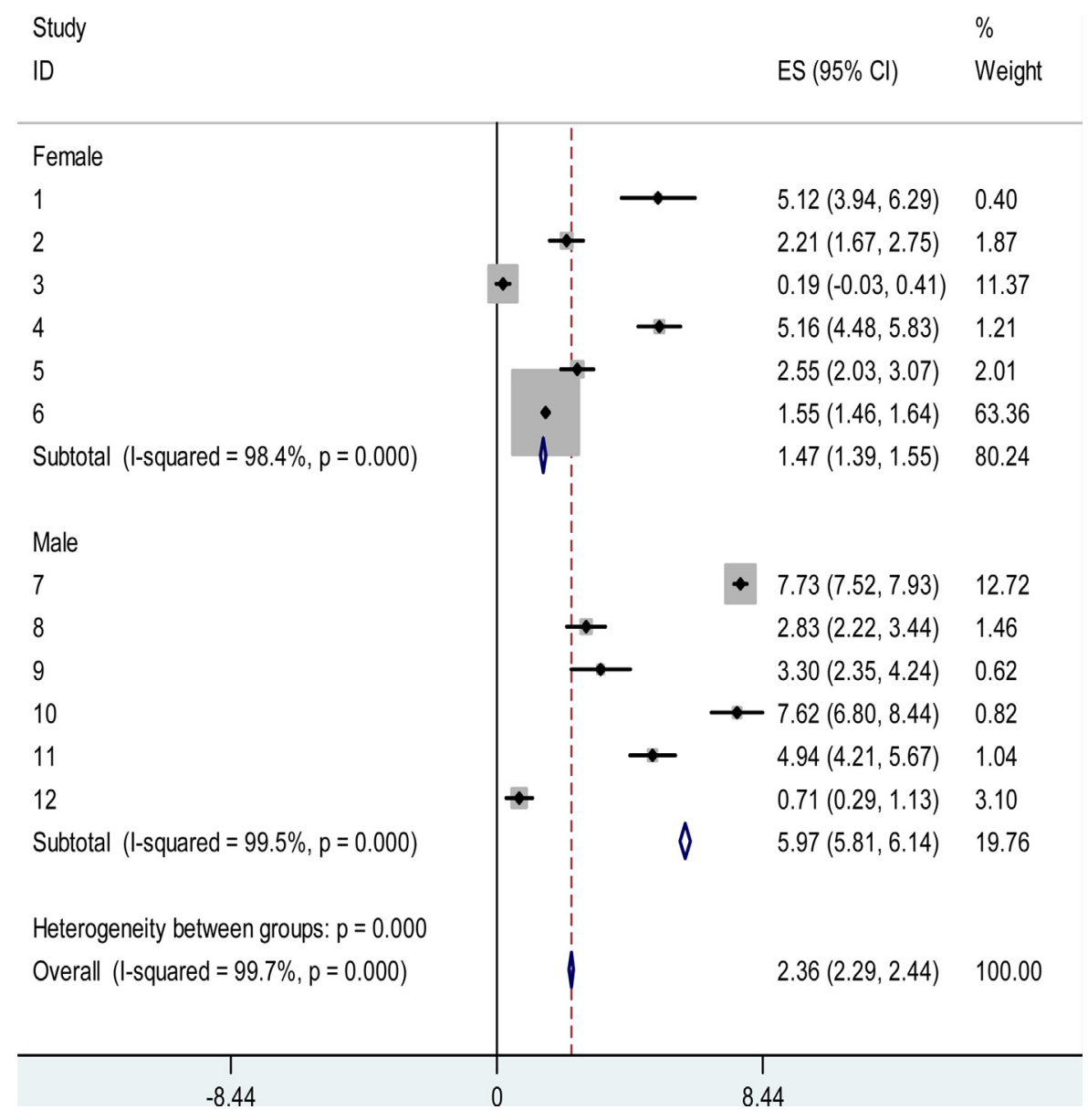

Fig. 2. Forrest plot of Pooled estimation meta-analysis of the incidence of Leukemia in male and female in Iran. 


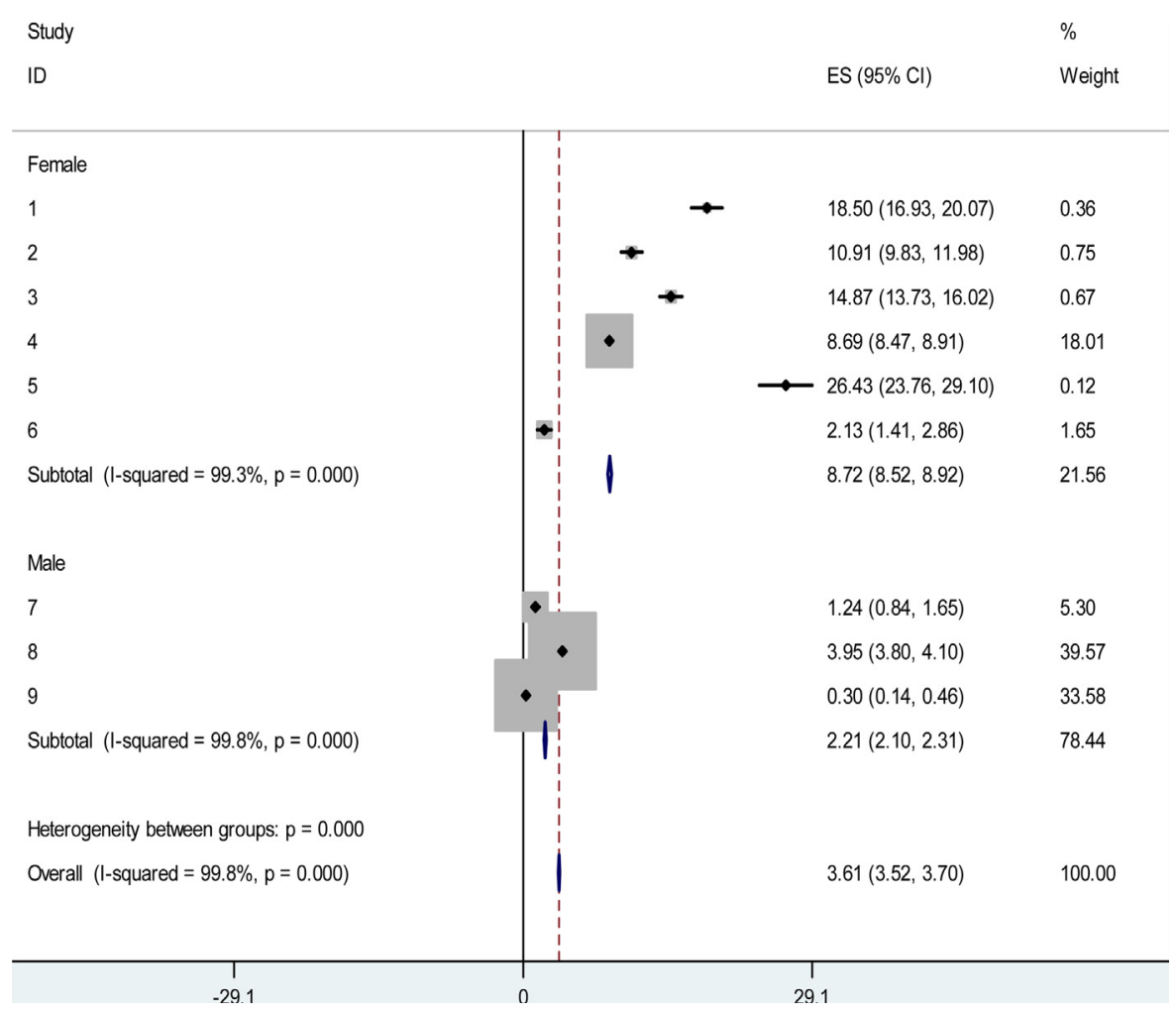

Fig. 3. Forrest plot of Pooled estimation meta-analysis of the incidence of Breast cancer in male and female in Iran.

that in line with our results partly. ${ }^{17}$ Also in females, cancer of the breast and in males, leukemia was at the top of the common cancers reported by Mehrabani et al. ${ }^{14}$ Zeinalzadeh et al expressed the most frequent cancers among males and females were stomach and breast, respectively. Also explained most common cancers in both sexes included breast, stomach, skin, bladder, esophagus, colon, lung, prostate, blood and thyroid. ${ }^{19}$ Sajadi et al reported the five most common cancers in males (by ASR) are stomach per, esophagus, colon and rectum, bladder and leukemia, and in females the five most common cancers are breast, esophagus, stomach, colon and rectum, and cervix uteri. ${ }^{30}$ Hashemi et al compared the findings of their study and results of western countries researches which indicates high-grade lymphomas are more common in Iran. ${ }^{31}$ Kolahdoozan et al in a review research indicates leukemia in males placed on the fifth rank of the five most common cancers. ${ }^{3}$

In contrast in the United States lung, breast, prostate, and colorectal cancer have a major effect on the total incidence of cancer. As well as according to World Health Organization statistics, among females, breast, colorectal, lung, cervix, and

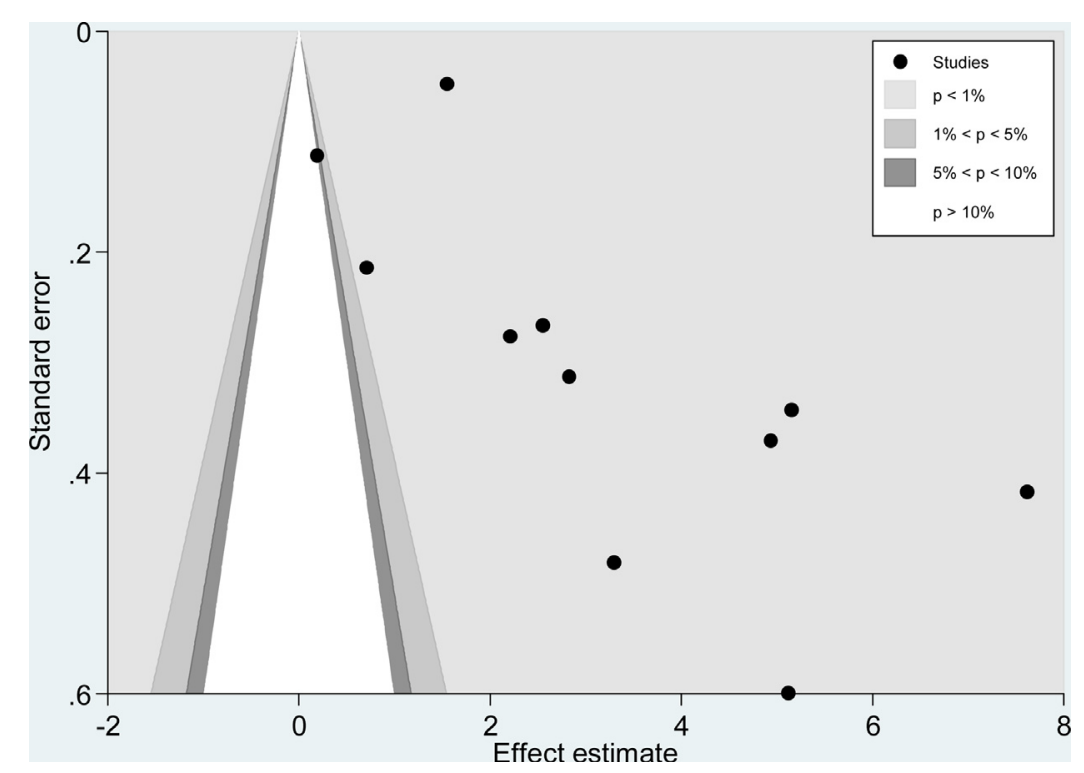

Fig. 4. Funnel plot of Pooled estimation meta-analysis of the incidence of cancer in male and female in Iran. 
stomach are the most commonly diagnosed cancer sites. Also lung, prostate, colorectal, stomach, and liver cancer were the 5 most common sites of cancer diagnosed in 2012 among men which approximately aligned with obtained results of this review. However it's not clear the main cause of above-mentioned cancers but it seems a multidimensional pathogenesis to be involved in developing these conditions which including a combination of genetic and environmental factors. ${ }^{32}$

Also our results showed the highest cancer incidence in Iran related to Golestan province. Of course it must be stressed the majority of studies included in this systematic review and as well as previous studies in the field of cancer incidence in Iran have been carried out In the mentioned provinces (Table 3 ). It should be noted the observed differences in the rate of incidence between various regions suggests an important factor in recognizing the risk factors. ${ }^{33}$ For example based on previous studies the high-risk regions of Iran which are susceptible to develop some of the cancers such as gastrointestinal (GI) are northern and northwestern areas. In two provinces of Iran which are located in the Caspian littoral and called Mazandaran and Golestan, the high incidence of GI cancers observed in both sexes. The highest incidence of GI cancers belongs to Ardabil in northwestern of Iran. As well as The Semnan, Golestan, East Azerbaijan and Tehran provinces have high rates of GI cancers in men and women. Kerman which is a province in the south of Iran, unlike to the northern areas, indicated a fewer incidence of GI cancers. ${ }^{34}$ In addition, GI cancers are multi-factorial diseases and arise from prolonged exposure to different carcinogens which lead to permanent damage of cells. Smoking, high consumption of salted food prepared the traditional method and frequent consumption of red meat which has been seen frequently among the cancer patients in the said provinces of Iran in previous studies. ${ }^{15}, 35$

On the other hand, the maximum incidence rate was seen in patients over 65 years old. Despite it is highly recommended screening test should be done after specific ages, especially in individuals at risk, or in those who have positive family history of cancer, unfortunately in our country, the public and the individual cancer-screening program are not done routinely. It can be said that although Iranian population in Suburb have a high illiteracy level, they are not sufficiently aware of the importance of screening test. Typically, their disease is detected at the end stage and persons with a specific condition (similar to the ones mentioned above) not examined routinely. In more advanced areas which persons have more access to specialized institutions and may be screened by their own physicians but it is not always the case.

As the final note, it should be concluded that the incidence of cancer totally and some kinds of it is significant in Iran and there is an increasing process. Since life expectancy and elderly people are increasingly in Iran, in the future it is expected that the population patients with cancer will grow quickly. The first priorities for health policymakers should be Development, establishment and implementation of Comprehensive National Cancer Control Program; because in the next decades the increased incidence rates of cancer will lead to the health system could not the response the demands regarding diagnosis, treatment and palliation. It is strongly advised to supply its national protocols and to coherent it in the primary health care settings.

Several limitations need to be mentioned when interpreting the study. First, our basic data extracted from previous studies in the field of gastrointestinal cancers incidence by age, sex, and region. Second, our information was limited to data that registries had recorded and our method in data investigating was retrospective and due to lack of access to more detailed information such as the number of new cases of cancer and population at risk within the coverage area. In fact, these two parameters are required for calculating the incidence of a disease.

\section{Financing}

The study was not financed by institutional and/or private resources.

\section{Conflict of interest}

The Authors have no conflicts of interest and the signature file is attached

\section{Acknowledgment}

This study hasn't acknowledgment section

\section{References}

1. Torres LA, Bray F, Siegel R, Ferlay J, Lortet-Tieulent J, Jemal A. Global cancer statistics, 2012. Cancer J Clin. 2015;65(2):87-108.

2. World Health Organization.Cardiovascular diseases (CVDs) 2012. Available at: http://www.who.int/mediacentre/factsheets/fs317/en/. Accessed 28.01.16.

3. Kolahdoozan Sh Sadjadi A, Radmard AR, Khademi H. Five Common Cancers in Iran. Arch Iran Med. 2010;13(2):143-146.

4. World Health Organization Cancer Country Profiles, 2014. Available at: www. who.int/entity/cancer/country-profiles/irn_en.pdf-34k . Accessed 29.07.2015.

5. Shaibani KH, Mortazavi S, Azadeh P. The Changing Trend in Cancer Incidence in Iran. Iran J Surg. 2004;12(31):25-30.

6. Nordahl H, Hvidtfeldt UH, Diderichsen F, Rod NH, Osler M, Frederiksen BL, et al. Cohort profile: the social inequality in cancer (sic) cohort study. Int J Epidemiol. 2014;1-9.

7. Rozen P, Liphshitz I, Barchana M. Changing epidemiology of colorectal cancer makes screening sigmoidoscopy less useful for identifying carriers of colorectal neoplasms. Dig Dis Sci. 2012;57(8):2203-2212.

8. The Importance of Epidemiology. Epidemiology fact sheet, 2011. Available at: http://www.cdc.gov/24-7/CDCFastFacts/epidemiology.html. Accessed 29.07.15.

9. Bray F, Ren JS, Masuyer E, Ferlay J. Global estimates of cancer prevalence for 27 sites in the adult population in 2008. Int J Cancer. 2013;132:1133-1145.

10. Which is the most appropriate guidelines for systematic review of observational studies PRISMA or MOOSE. Available at: www.researchgate. net/post/2. Accepted 25.08.15.

11. MOOSE: Sanjari Moghaddam A, Nazarzadeh M, Noroozi R, Darvish H, and Mosavi Jarrahi A. XRCC1 and OGG1 Gene Polymorphisms and Breast Cancer: A Systematic Review of Literature. Iran J Cancer Prev 2016; 9 (1):e3467. dOI:10.17795/ijcp-3467.

12. Somi MS, Mirinezhad K, Farhang S, Jazayeri E, Sani A, Seif-Farshad M, et al. Gastrointestinal cancer occurrence in east Azarbaijan: a five year study from North Western Iran. Asian Pac J Cancer Prevent. 2006;6(7):309-312.

13. Semnani Sh Sadjadi A, Fahimi S, Nouraie M, Naeimi M, Kabir J, et al. Declining incidence of esophageal cancer in the Turkmen Plain, eastern part of the Caspian Littoral of Iran: A retrospective cancer surveillance. Cancer Detect Prevent. 2006;30(1):14-19.

14. Mehrabani D, Tabei SZ, Heydari ST, Shamsina SJ, Shokrpour N, Amini M, et al. Cancer occurrence in Fars Province, Southern Iran. Iran Red Crescent Med J. 2008;10(4):314-322.

15. Somi MS, Farhang S, Mirinezhad K, Naghashi h S, Jazayeri E, Sani A, et al. Cancer in East Azerbaijan, Iran: results of a population-based cancer registry. Asian Pac J Cancer Prev. 2008;9:327-330.

16. Mirzaei M, Hosseini SA, Ghoncheh M, Soheilipour F, Sh Soltani, Soheilipour F, Salehiniya H. Epidemiology and trend of head and neck cancers in Iran. Global J Health Sci. 2015;8(1):189-193.

17. Mousavi SM, Gouya MM, Ramazani R, Davanlou M, Hajsadeghi N, Seddighi Z. Cancer incidence and mortality in Iran. Ann Oncol. 2009;20(3):556-563.

18. Safaee A, Fatemi SR, Ashtari S, Vahedi M, Moghimi-Dehkordi B, Zali R. Four years incidence rate of colorectal cancer in Iran: A survey of national cancer registry data? implications for screening. Asian Pac J Cancer Prev. 2012;13:2695-2698.

19. Zeinalzadeh AH, Hosseini R, Abdullahi L. Survey of epidemiology of cancers in the patients above 15 years old in East Azerbaijan Province: Iran 2013. J Ardabil Univ Med Sci. 2015;15(1):46-55.

20. Taefi A, Nouraie M, Ghorbani A, Fakheri H, Zahedi MJ, Semnani Sh. The incidence of pancreas and Billiary ducts cancers in Iran: a population based study. Govaresh. 2008;13(4):217-222.

21. Esmailnasab N, Gh Moradi, Zareaie M, Ghaderi A, Gheitasi B. Epidemiology and Incidence of cancers in people over 15 years of Kurdistan province. Sci J Kurdistan Univ Med Sci. 2005;11:18-25.

22. Hashiani A, Farahmand M, Hasanzadeh J, Raee M. The incidence of lung cancer in fars province: results of a population-based cancer registry (2001-2008). Payesh Quart. 2012;11(4):477-483.

23. Mirzaei M, Razi Si Ghoncheh M, Mohammadian A, Salehiniya H. Skin cancer incidence rate and trend in 2004-2008 in Tehran province. Dermatol Cosmet. 2014;5(4):193-199. 
24. Kohi F, Salehinia H. The trend of incidence of bladder cancer in Iran: 20032009. J Urmia Univ Med Sci. 2015;26(1):1-9.

25. Ansari R, Mahdavinia M, Sadjadi A, Nouraie M, Kamangar F, Bishehsari F. Incidence and age distribution of colorectal cancer in Iran: results of a population-based cancer registry. Cancer Lett. 2006;240:143-147.

26. Zahedi MJ, Darvishmoghadam S, Hayatbakhsh Abbasi M, Zeinalinejad H. The incidence rate of gastrointestinal tract cancers in Kerman province during 1996-2000. J Kerman Univ Med Sci. 2005;12(3):153-158.

27. Khabazkhub M, Mohagheghi SMA, Mousavi-Jarahi SAR, Javaherforoush A, Pedramfar M, Moradi A. The incidence of gastrointestinal tract cancers in Tehran Province during 1998-2001. Sci J Gorgan Univ Med Sci. 2009;11(4):4450.

28. Yavari P, Hislop TG, Bajdik C, Sadjadi A, Nouraie M, Babai M, Reza Malekzadeh R. Comparison of cancer incidence in Iran and Iranian immigrants to British Columbia. Canada Asian Pac J Cancer Prev. 2006;7:86-90.

29. Siegel R, Miller KD, Jemal A. Cancer statistics, 2015. CA Cancer J Clin. 2015;65:5-29.
30. Sadjadi A, Nouraie M, Mohagheghi MA, Mousavi-Jarrahi A, Malekezadeh R, Parkin DM. Cancer occurrence in Iranin 2002, an international perspective. Asian Pac J Cancer Prev. 2005;6:359-363.

31. Hashemi-Bahremani M, Parwaresch MR, Tabrizchi H, Gupta RK, Raffii MR Lymphomas in Iran. Arch Iranian Med. 2007;10(3):343-348.

32. Youssef F, Cardwell C, Cantwell MM, Galway K, Brian T, Johnston BT, Murray L. The incidence of esophageal cancer and high-grade dysplasia in Barrett's Esophagus: a systematic review and meta-analysis. Am J Epidemiol. 2008; 168:237-249.

33. Mobasheri M, Ahmadi A. Incidence patterns and spatial analysis of the most common cancers in southeastern iran using geographic information system (GIS). Acad J Cancer Res. 2014;7(2):141-145.

34. Malekzadeh R, Derakhshan MH, Malekzadeh Z. Gastric cancer in Iran epidemiology and risk factors. Arch Iranian Med. 2009;12(6):576-583.

35. Zarea K, Beiranvand S, Ghanbari S, Tuvesson H. Incidence of gastrointestinal cancers in Iran: a systematic review. Jundishapur J Chronic Dis Care. 2017;6(1): e37224. 